\title{
ARQUITECTURA PARA EL CULTO. UN PROYECTO INÉDITO DE VIRGILIO MATTONI
}

\author{
SACRED ARCHITECTURE. A VIRGILIO MATTONI'S \\ UNRELEASED PROJECT
}

\author{
Álvaro Cabezas García \\ alvarocabezasgarcia@gmail.com
}

\begin{abstract}
Virgilio Mattoni diseñó en 1886 un altar portátil para la novena de la Virgen de la Paz en la parroquia de Santa Cruz de Sevilla. El dibujo, hasta ahora desconocido, presenta rasgos definitorios de la estética de su autor e interesantes pistas acerca de la solución que propuso, de la mano de la arquitectura efímera, a la hora de resolver la necesidad de un nuevo marco para el culto.

Palabras clave: Virgilio Mattoni, arquitectura efímera, proyecto, tabernáculo, liturgia.
\end{abstract}

Virgilio Mattoni designed in 1886 a portable altar for the novena of the Virgen de la Paz in the Santa Cruz's parish of Seville. The drawing, so far unknown, presents defining features of the aesthetics of its author and interesting clues about the solution proposed by the hand of the ephemeral architecture, solving the need for a new framework for the cult.

Keywords: Virgilio Mattoni, ephemeral architecture, project, tabernacle, liturgy.

El ilustrado Eugenio de Llaguno y Amírola (1724-1799), se jactaba en su obra Noticias de los arquitectos y arquitectura de España desde su restauración de haber instigado al arzobispo de Sevilla, Alonso Marcos de Llanes Argüelles (1732-1795), a sustituir el "monstruoso"1 retablo que había ejecutado en 1745 Felipe Fernández del Castillo ${ }^{2}$ para el testero del templo del convento de clérigos

${ }^{1}$ Así lo calificó en LLAGUNO Y AMÍROLA, Eugenio: Noticias de los Arquitectos y de la Arquitectura en España desde su restauración. Ilustradas y acrecentadas con notas, adiciones y documentos por Juan Agustín Ceán Bermúdez. Madrid, 1829, vol. $4^{\circ}$, p. 50.

${ }^{2}$ Ofrece más datos al respecto GÓMEZ PIÑOL, Emilio: "Noticias y acontecimientos sociales y artísticos de la Hermandad Sacramental de la antigua parroquia de Santa Cruz”, en Santa Cruz y el Cristo de las Misericordias. Sevilla, 2004, pp. 38 y 39. 
menores de Sevilla por una solución espacial que diese correcta respuesta estética a las inclinaciones del momento. Como consecuencia, se colocó en 1792 un sencillo tabernáculo en forma de templete en medio de la capilla mayor ${ }^{3}$. Fue Blas Molner († 1812), por entonces director de la Clase de Escultura de la Real Escuela de las Tres Nobles Artes de Sevilla, el encargado de diseñarlo con una estructura capaz de acoger el manifestador eucarístico, combinando la reformulación que Bramante había realizado del tholos griego en el tempietto de San Pietro in Montorio, con la utilización de la cubierta abovedada ensayada, entre otros, por Ventura Rodríguez en 1779 en el diseño del tabernáculo que pretendía presidiera el altar mayor de la basílica de Covadonga ${ }^{4}$. La obra, de planta circular y con doce columnas en cuatro grupos de tres (hoy solo se conservan ocho), que sostienen una bóveda rematada por una dinámica escultura de la Fe, había sido realizada en madera imitando mármoles polícromos ${ }^{5}$. El hecho de ser el primer tabernáculo de estas características que se erigió en suelo hispalense -a lo que habría que añadir la ubicación del nuevo coro en el presbiterio siguiendo las recomendaciones de los teóricos del arte, cuyos presupuestos litúrgicos se presentaban bien delimitados al respecto- ${ }^{6}$, provocó cierto efecto de emulación en algunos otros ámbitos del Arzobispado hispalense ${ }^{7}$. Sin embargo, la conversión de

${ }^{3}$ Para su construcción se contó con las limosnas de los fieles. Sobre "los excluyentes gustos neoclásicos” y su repercusión en este caso concreto, vid. RECIO MIR, Álvaro: "El peso inmenso de la Historia: Neoclasicismo e Historicismo", en HALCÓN, Fátima; HERRERA, Francisco y RECIO, Álvaro: El retablo sevillano. Desde sus Orígenes a la Actualidad. Sevilla, 2009, p. 392.

${ }^{4}$ Vid. MADRID ÁLVAREZ, Vidal de la: "El arquitecto Ventura Rodríguez y Covadonga: La accidentada historia de un proyecto frustrado", Liño. Revista Anual de Historia del Arte, 15, 2009, pp. 199-220. El diseño del tabernáculo aparece reproducida en la p. 213.

${ }^{5}$ A raíz de la colocación permanente, en la década de los años setenta del siglo XX, de la Virgen de la Paz en el interior del tabernáculo, se retiraron las cuatro columnas interiores que aparecían en el diseño original. Vid. YRUELA ROJAS, Fernando: "La Hermandad de Santa Cruz. Cien años de Historia", en Santa Cruz y el Cristo de las Misericordias. Sevilla, 2004, p. 183. El traslado de la imagen contó con la aquiescencia del párroco del momento, Juan Lemus Bengoechea.

${ }^{6}$ Los sacerdotes "parece más conforme a la razón que pasen al presbiterio" había apuntado el MARQUÉS DE UREÑA, Gaspar de Molina y Saldívar: Reflexiones sobre la arquitectura, ornato y música del templo: contra los procedimientos arbitrarios sin consulta de la Escritura Santa, de la disciplina rigorosa (sic), y de la crítica facultativa. Madrid, 1785, p. 310. Para conseguir este objetivo, se desarrolló por parte de algunos ilustrados la teoría del "coro reformado", ampliamente desarrollada por PONZ, Antonio: Viage de España, en que se da noticia de las cosas más apreciables, y dignas de saberse, que hay en ella. Tomo XVI. Madrid, 1791, p. 407, en relación con el coro de la Catedral de Jaén.

${ }^{7}$ Otros templetes análogos se colocaron para presidir las parroquias de San Miguel, El Sagrario, San Ildefonso, la capilla de San Pedro de Alcántara, el convento de las Dueñas o, ya fuera del ámbito capitalino, San Pedro de Carmona. Vid. RECIO MIR, 
este templo en sede parroquial de Santa $\mathrm{Cruz}^{8}$ y el afloramiento de nuevas prácticas devocionales, trajeron consigo necesidades congregacionales que presentaban la ubicación de dicha máquina como un elemento distorsionador del culto, algo que, con soterrada vigencia, se ha mantenido incluso hasta la actualidad. La solución aportada por Virgilio Mattoni de la Fuente (1842-1923), en el proyecto inédito de su mano que aquí presento es una de las más interesantes desde el punto de vista estético.

Efectivamente, con el recién adquirido carácter de parroquia, llegaron al antiguo convento de clérigos menores las corporaciones que habían radicado en el desaparecido inmueble: la Hermandad Sacramental y la Hermandad de la Virgen de la Paz. Esta última veneraba una imagen bajomedieval de la Virgen con el Niño que fue colocada en el retablo del lado de la Epístola del crucero. En fechas próximas a noviembre de 1874, el referido retablo sufrió un incendio que afectó a la imagen, hecho que provocó no mucho después que acabara siendo sustituida por la talla atribuida a Jerónimo Hernández de la Estrada (1540-1586), y que bajo la advocación del Rosario había presidido el retablo mayor del antiguo convento de San Pablo, por esos años convertido en parroquia de Santa María Magdalena ${ }^{9}$. La nueva Virgen de la Paz aglutinó en torno suyo la devoción de los feligreses de Santa Cruz hasta el punto de que pronto comenzaron a tributársele cultos

\footnotetext{
Álvaro: "El peso inmenso...", op. cit., p. 396. Sobre este asunto también sería necesario ahondar en el hecho de que los tabernáculos de la etapa neoclásica no presentarían una novedad tipológica para el culto, sino que rescatarían los ensayos que, en el ámbito hispánico, apostaban por los elementos centralizados para el desarrollo de la liturgia como ocurría en las basílicas patriarcales romanas. Ejemplos así podrían rastrearse en el altar cuadriforme proyectado por el cardenal Manuel Arias y Porres (1638-1717), para la capilla mayor de la colegial de El Salvador o el proyectado para el Sagrario en 1662, y en el caso novohispano, que mantiene algunos testimonios en pie. Vid. GÓMEZ PIÑOL, Emilio: La Iglesia Colegial del Salvador. Arte y sociedad en Sevilla (Siglos XIII-XIX). Sevilla, 2000, pp. 219 y siguientes; RECIO MIR, Álvaro: “Aquella segunda fábrica que ha de estar en lo interior de la otra. Los proyectos de tabernáculo para el Sagrario de la Catedral de Sevilla y su realización efímera en 1662", Archivo Español de Arte, 2003, 301, pp. 55-70; y HERRERA GARCÍA, Francisco y SÁNCHEZ SÁNCHEZ, José María: "La polémica sobre la ubicación del altar mayor de la catedral de México y la adopción del tabernáculo-ciprés exento", Fronteras de la historia: revista de historia colonial latinoamericana, 18-2, 2013, pp. 133-165.

${ }^{8}$ En 1810 se produjo el derribo de la antigua parroquia de Santa Cruz y el traslado de esta institución al convento de clérigos menores. En 1814 los religiosos lo recuperaron para sí, pero la desamortización de Mendizábal (1836-1837), restituyó definitivamente el uso parroquial al mencionado inmueble. A este respecto, vid. HEREDIA MORENO, María del Carmen y ROMERO, Purificación: "La antigua y la actual parroquia de Santa Cruz", Archivo hispalense: Revista histórica, literaria y artística, 175, 1974, pp. 139-170.

${ }^{9}$ La cronología ha sido probada documentalmente por YRUELA ROJAS, Fernando: "La Hermandad de...", op. cit., pp. 174-183.
} 
de impetración en forma de novena ${ }^{10}$. Siguiendo la costumbre que regía que las imágenes se desplazaran desde su ubicación habitual hasta el altar mayor con objeto de dotar el culto de gran solemnidad, y teniendo en cuenta las características de la parroquia de Santa Cruz -en la que ni el testero del antiguo convento, ni el tabernáculo que lo presidía habían sido pensados para el culto de las imágenes, sino para el eucarístico primordialmente-, fue necesario idear un "altar de aparato" que remediase esta circunstancia temporalmente. Es en este punto donde hace su aparición la arquitectura efímera para rubricar la alta dignidad de la que era acreedora la imagen a la que iba a rendirse el culto ${ }^{11}$.

Siguiendo esta lógica, el hermano mayor de la corporación, Joaquín García, instó en el año 1886 a los cofrades Manuel Pavía y Pereira y José Morón Cansino, se dirigieran a Virgilio Mattoni -que tenía taller abierto en el barrio de Santa Cruz-, para rogarle realizara un proyecto de altar portátil que pudiera utilizarse para la novena de la Virgen de la Paz. El pintor se ocupó de ello y entregó a los representantes de la hermandad un diseño que ha permanecido sin estudiar hasta el momento ${ }^{12}$ y que había sido custodiado por uno de los comitentes hasta 1930, estando desde entonces su conservación a cargo de la Hermandad de Santa Cruz ${ }^{13}$. Se desconocen las causas por las que este proyecto no pudo materializarse, pero

${ }^{10}$ La generalización de esta liturgia de impetración (novenas, octavas, septenarios, quinarios, triduos), en las hermandades de Sevilla no se produjo hasta las últimas décadas del siglo XVIII. Así lo afirma DELGADO ABOZA, Francisco Manuel: "Arquitecturas efímeras: Los Altares de Cultos”, en El poder de las imágenes. Iconografía de la Semana Santa de Sevilla. Sevilla, 2000, p. 154.

${ }^{11}$ Este era el proceso habitual. Sobre el asunto, vid. el estudio de MARTÍNEZ LARA, Pedro M.: "Una arquitectura para el culto. La evolución de los altares de aparato en la Hermandad de la Macarena", en Esperanza Macarena. Historia, Arte, Hermandad. Sevilla, 2013, vol. III, pp. 264 y 268.

${ }_{12}$ Tan solo había sido mencionado, y no con demasiada exactitud, por YRUELA ROJAS, Fernando: "La Hermandad de...", op. cit., p. 177: "Existe un boceto de retablo firmado por Virgilio Mattoni y fechado en 1876 (sic), en el cual aparece la nueva imagen de la Virgen de la Paz".

${ }^{13}$ La Hermandad de la Virgen de la Paz, habiendo decaído, se fusionó con la Sacramental de Santa Cruz en 1907 y esta, asimismo, hizo lo propio con la Hermandad penitencial que rendía culto al Santísimo Cristo de las Misericordias en 1966. El dibujo se encuentra enmarcado y colgado en el salón de exposición de la Hermandad Sacramental de Santa Cruz, en las dependencias anejas a las tribunas de la parroquia del mismo nombre. En el reverso aparece la siguiente inscripción: "Proyecto de altar portátil para la Novena de la Smma. Virgen de la Paz, de la Parroquia / de Sta. Cruz de Sevilla, ejecutado por el Yltmo. Sor. D. Virgilio Mattoni en el / año 1.886 a ruego de los Sres. D. Manuel Pavia y Pereyra y D. José Morón I y Cansino. I A instancias del Sor. Cura y Hermano Mayor, que lo era en aquel tiempo el Sor. I D. Joaquín García, ha sido conservado por el firmante esperando tiempos propicios para su / ejecución. Sevilla 15 de mayo de 1930. José Morón Cansino (rúbrica)". 
pudieron ir desde el coste de su ejecución hasta el problema que suponía su colocación delante del tabernáculo elaborado por Molner. El caso es que se trata de un importante documento que permite ahondar en la estética que esos años dominaba el trabajo de Mattoni y en la solución de altar de aparato que propuso como alternativa efímera a la permanente distribución espacial del templo.

Lo primero que habría que señalar es que Mattoni ha realizado aquí un ejercicio compositivo de acumulación de elementos tratados de forma independiente y luego unidos en el proyecto, circunstancia que permite que algunos de ellos aparezcan bajo diferentes perspectivas. Lo segundo sería que el carácter de boceto de este dibujo hace muy difícil discernir el nivel de guía pretendido en este, a la hora, por ejemplo, de conseguir la decoración exacta de los balaustres o del angrelado del arco del dosel que cobija la Virgen, así como la peculiaridad de presentarla con corona medieval y con el Niño en posición y escorzo diferente al original.

En cuanto al análisis de la composición que propone habría que decir que se conforma en dos planos: el principal o del sacrificio y reserva eucarística, y el secundario o de la veneración de la imagen mariana. El primero cuenta con una mesa de altar sobre la que se distribuyen las tres gradillas litúrgicas y, sobre ellas, un tabernáculo-manifestador para acoger un sagrario o reserva, de base hexagonal, con seis columnas corintias y torsas de seis espiras -siguiendo el tratado de Vignola-, y con entablamento sobre el que se dispone una estructura cupuliforme, con tres niveles decrecientes, rematada en cruz. El segundo cuenta con un primer cuerpo de planta cuadrangular, un segundo de planta ochavada animado por balaustres con capitel compuesto en los chaflanes y terminado en cornisa, y por último, un tercero muy bajo y con cartela -vacía en el proyecto-, con una moldurita de remate y sobre el que se sostiene una peana con formas animales parece que se trata de pavos reales-, que mantiene un trono con dosel que sirve para cobijar la imagen de la Virgen de la Paz, sedente en su sillón, sostenido este por balaustres y dosel con planta hexagonal rematada en una cúpula con adornos flamígeros. Se muestran también dos candeleros para sendos cirios a los lados del trono y pedestales sobre la peana con candelabros de siete brazos. Esta estructura decreciente recibe un cobijo arquitectónico de un par de soportes abalaustrados que sostienen una cornisa con frontón roto y curvo, de la que penden caídas textiles con borlas. A los lados del conjunto, y sobre pedestales, se dispone una suerte de candeleros abalaustrados biomórficos que rematan en un pebetero donde se dispone parte de la candelería. Todo este aparato se separa del fondo del presbiterio por un cortinaje que, mediante argollas, pende de una barra de metal a la altura de la cornisa, lo que permitiría ocultar en todo o en parte el tabernáculo de Molner que preside la parroquia. Sobre esta estructura habría que distribuir la candelería, no prevista en su totalidad por Mattoni en este diseño ${ }^{14}$.

${ }^{14}$ Mattoni conoció en 1884 el que se convertiría en "su amigo del alma": el escultor Adolfo López Rodríguez (1862-1943). Con él colaboró en determinadas ocasiones, de tal 
La valoración de este dibujo de Mattoni permite ratificar que la preocupación que siempre tuvo por la conservación e intervención sobre el patrimonio comenzó en fecha más temprana de lo que se conocía hasta ahora ${ }^{15}$. En este mismo año de 1886 fue nombrado académico correspondiente en Sevilla de la de San Fernando de Madrid y al año siguiente lo fue como numerario de la de Bellas Artes hispalense al ocupar la vacante dejada por Jiménez Aranda ${ }^{16}$. Estos hechos y el premio recibido por su obra de mayor consideración, Las postrimerías de Fernando III el Santo (1887), harán que adquiera la consideración de pintor consagrado al arte y la religión de su ciudad. Llegaba a la cúspide de su carrera cuando todavía se le conocía como pintor historicista a raíz de su reciente vuelta de la estancia romana (1872-1874), hecho que siguió reflejándose en su producción ${ }^{17}$. Sin embargo, las características del dibujo que traigo a colación prefiguran ya las que desarrollará primordialmente en los años noventa del siglo XIX relacionadas con el gusto por el pasado medieval de inspiración cristiana, formas que lo acercaron "a la asimilación de algunas tendencias contemporáneas"18.

forma que mientras Mattoni diseñaba obras de intervención, López se encargaba de ejecutarlas. Así lo hicieron en la capilla del Sagrado Corazón de la parroquia de San Andrés (1893), en la restauración de Valme de Dos Hermanas (1894), en el convento de Capuchinos (1895) y en la sillería del coro de la Catedral de Sevilla (1897). Sobre esta relación, vid. LAFITA, Teresa: "Otras obras inéditas del pintor Virgilio Mattoni de la Fuente: San Emigio, Retrato de Adolfo López, Cuaderno de Apuntes y Santa Isabel de Hungría", Atrio: revista de historia del arte, 8-9, p. 178. Podría pensarse que, de haberse materializado, este altar para la Virgen de la Paz hubiera podido ser ejecutado por López. Así, quizá hubiese sido la más temprana empresa de colaboración entre ambos.

${ }^{15}$ Es muy probable que Mattoni realizara este encargo de forma totalmente desinteresada, simplemente como producto de su convicción religiosa. Así ocurrió en otros casos de mayor enjundia, como el del proceso de restauración de la Virgen de Valme, para el que hubo de aportar una serie de dibujos. Cfr. PÉREZ CALERO, Gerardo: El pintor Virgilio Mattoni. Sevilla, 1977 (1996), p. 15. Sobre sus variadas vertientes culturales de implicación cívica (poeta, historiador del arte, docente, pensador), y su relación institucional, vid. PÉREZ CALERO, Gerardo: "Virgilio Mattoni y las corporaciones artísticas sevillanas", Boletín de Bellas Artes, 4, 1976, pp. 181-194.

${ }^{16}$ Cfr. Ibídem, p. 187.

${ }^{17}$ Vid. PÉREZ CALERO, Gerardo: El pintor Virgilio..., op. cit., p. 50, consiguió se le considerara mucho más que "un pintor de historia" formado con Eduardo Cano o un "tardorromántico" emulador de José Domínguez Bécquer.

${ }^{18}$ Estas serían, indistintamente, el simbolismo, el modernismo, el prerrafaelismo inglés y el movimiento de los nazarenos alemanes. Así lo cree VALDIVIESO, Enrique (a y b): a) Pintura sevillana del siglo XIX. Sevilla, 1981, pp. 112-115; y b) Historia de la pintura sevillana. Siglos XIII al XX. Sevilla, 1986 (2002), pp. 438 y 439; y PÉREZ CALERO, Gerardo (a y b): "El simbolismo en la pintura sevillana (1880-1938)", Laboratorio de Arte: Revista del Departamento de Historia del Arte, 2, 1989, pp. 183-208; y b) "Obras inéditas 
Mattoni, pintor excepcional y de dibujo detallista y refinado, estaría con este proyecto de altar portátil aportando una solución sobre una necesidad espacial de culto en la parroquia de Santa Cruz. La fórmula que emplea es original y consecuente con su visión estética: "Renovar en Sevilla el estilo arcaico de los primitivos y quincentistas" ${ }^{\prime \prime}$. La mirada al pasado, una vez más, como recurso de los problemas planteados en el presente.

Fecha de recepción: 11 de septiembre de 2014

Fecha de aceptación: 28 de septiembre de 2014

simbolistas y nazarenas del pintor V. Mattoni”, Laboratorio de Arte: Revista del Departamento de Historia del Arte, 13, 2000, pp. 409-418.

19 Ápud. PÉREZ CALERO, Gerardo: El pintor Virgilio..., op. cit., p. 50. 


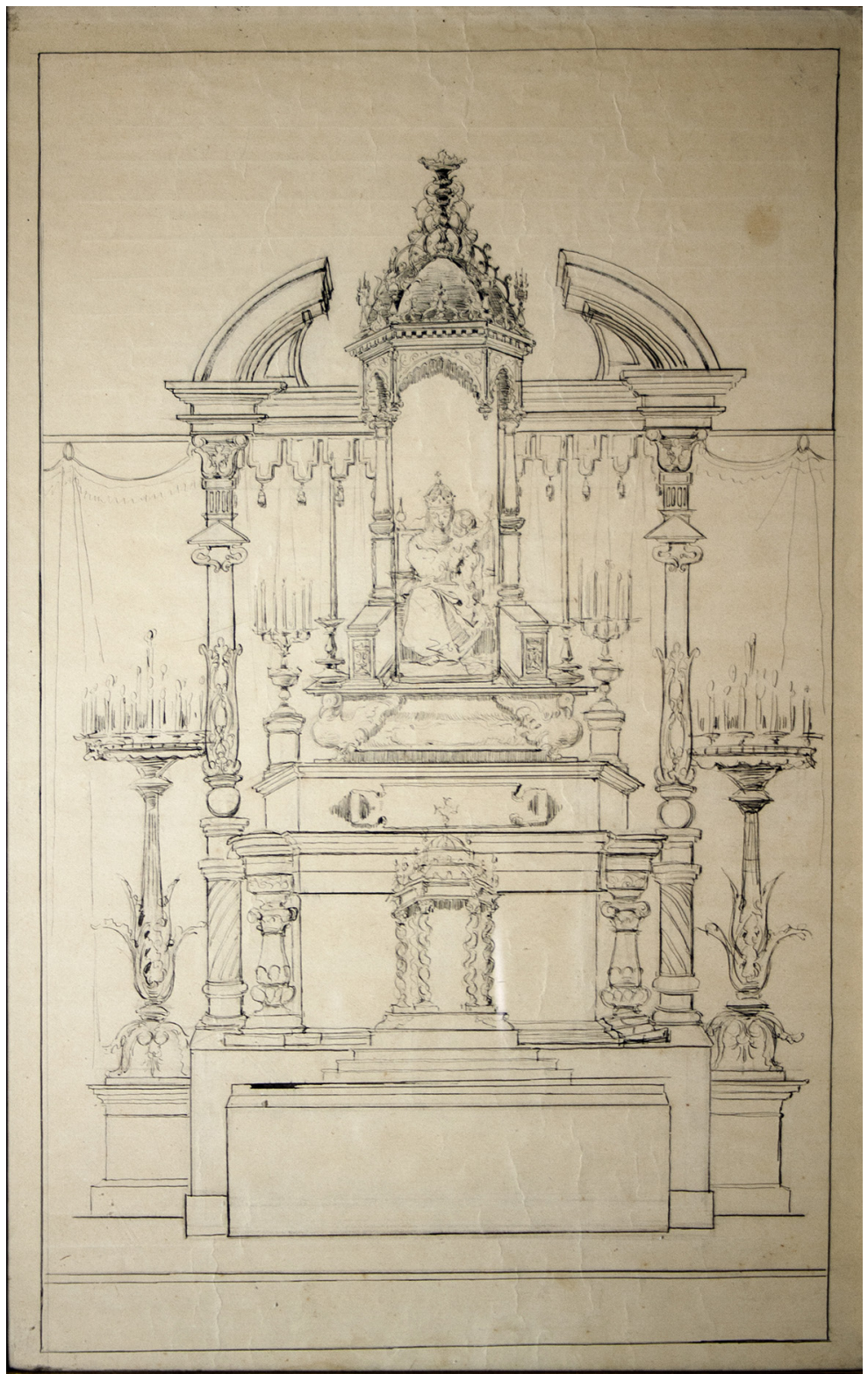

Figura 1. Proyecto de altar portátil para la Virgen de la Paz de la parroquia de Santa Cruz. Virgilio Mattoni. 1886. Hermandad de Santa Cruz. 


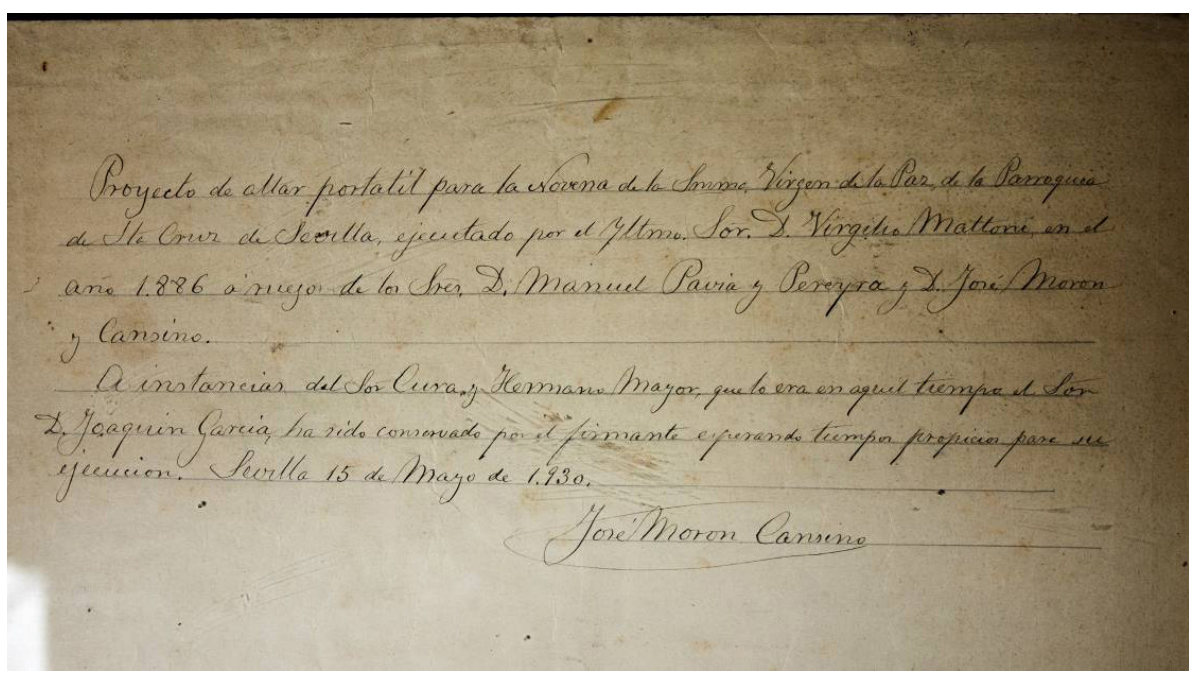

Figura 2. Inscripción en el reverso del proyecto. Virgilio Mattoni. 1886. Hermandad de Santa Cruz. 